\title{
Principais resultados, questões de pesquisas e nossas hipóteses
}

Tentamos responder nossas questões de pesquisa e validar ou não as hipóteses, sem perder de vista a participação dos professores durante as atividades, a heterogeneidade de suas formações anteriores, bem como suas histórias de vida.

Em busca de respostas para nossa primeira questão de pesquisa: Que Organização Didática os professores constroem para o ensino de números fracionários para a quinta série do Ensino Fundamental durante a formação?

Constatamos pela análise dos mapas conceituais, realizados com base na palavra-chave frações que, no primeiro mapa, realizado no início da formação, os professores enfatizaram técnicas e nomenclaturas referentes aos fracionários. No segundo, realizado depois da formação específica sobre fracionários a palavra fração não foi citada nem qualquer concepção de números fracionários, embora duas delas priorizem o conteúdo e uma o conhecimento.

Assim, acreditamos que os sentimentos de angústia provocados pela constatação do não saber de um conteúdo matemático que julgavam dominar, impediu-os de explicitar, tanto conceitos anteriores quanto os resultantes da formação.

Dessa forma, nossa questão é respondida por OM rígidas que focam a mobilização da concepção parte-todo em contextos que envolvem superfícies, em situações que são resolvidas pela técnica da dupla contagem das partes. Além da concepção de razão, que foi mobilizada como sinônimo de divisão com o predomínio da técnica da regra de três, justificada por raciocínios algébricos apoiados em noções de proporcionalidade.

A busca da resposta para esta questão levou-nos a observar algumas dificuldades dos professores em formação. Embora tivessem acesso a situações que associavam as várias concepções por meio de diversos tipos de tarefas e técnicas, eles apresentaram dificuldades em tomar decisões e colocá-las em prática para obter 
OD que mobilizassem OM mais amplas e, assim pudessem favorecer a construção de conhecimentos pertinentes às diversas concepções de fracionários pelos alunos.

Outro ponto a ser considerado foi a dificuldade em produzir em grupo, embora estivessem acostumados a trabalhar dessa forma como aprendizes de Geometria, na primeira fase de nosso projeto. Um dos impedimentos para essa produção em grupo pareceu-nos ser a dificuldade em colocar em prática decisões tomadas para a elaboração da OD.

Além disso, viram-se bloqueados pela percepção de seus não saberes, de forma tão profunda, que não conseguiam elaborar a sequência de ensino que pretendiam. Só foram se sentir à vontade para contribuir, de maneira consistente, quando a formadora apresentou a OD por ela elaborada. Era como se soubessem o que deveriam fazer, mas não como.

Mas, a maior dificuldade apresentada no tratamento do conteúdo e, de forma geral, foi fazer relações entre tarefas ou entre técnicas mostrando, muitas vezes, na falta de um olhar crítico para as situações, o não desenvolvimento de capacidades para construir ou analisar com certo objetivo.

Entendemos que essas dificuldades e a produção para o ensino baseado em regras prontas, localizadas em desenvolvimentos históricos mais recentes, devem-se à crença na aprendizagem por memorização. O que fica evidente quando afirmam que "razão é quociente", mesmo que na situação a divisão não faça sentido ou quando se surpreendem com a resolução de uma regra de três por tabela, sem explicitar uma letra como incógnita ou, ainda, quando procuram justificativas para a regra de divisão de números fracionários.

De forma geral, nossas análises permitiram indicar algumas mudanças nas concepções de números fracionários, não tanto por garantir que estejam aptos a promover ações formativas eficazes com autonomia para a aprendizagem do assunto por seus alunos, mas, por percebermos a conscientização do grupo da limitação do domínio que tinham desse conteúdo, além da não eficácia de um ensino baseado em regras, sem compreensão. Não acreditamos que possam voltar às antigas práticas para tratar de fracionários.

Embora iniciassem o processo buscando saídas para a aprendizagem dos alunos e afirmassem que estes nada sabiam a respeito de números fracionários, percebemos, no decorrer das atividades, a compatibilidade dessas afirmações com seus próprios não saberes que explicitados tornaram-se conscientes e os conduziram a momentos de angústias, incertezas e inseguranças.

Mesmo sendo necessários para a aprendizagem, tanto do conteúdo como de autonomia esses momentos nos revelaram que a reflexão a respeito do conteúdo provocada pela formação deve se aprofundar a ponto de perceber possíveis não saberes dos professores, para que esses possam ser tratados efetivamente e garantir alguma aprendizagem. Caso contrário, podemos correr o risco de provocar 
discussões superficiais que, momentaneamente, parecem surtir efeito, mas, que não produzem mudanças de práticas a longo prazo.

No entanto, essas formações precisam de tempo, muito tempo, para que realmente possam ser proveitosas para o professor e, consequentemente, para o aluno. Por isso, talvez seja mais coerente pensar no papel de um assessor de matemática que esteja em contato com os professores discutindo suas necessidades diárias que o ajude a analisar e preparar suas próprias ações formativas e não formações esporádicas e curtas que discutam, muitas vezes, assuntos que os professores não estão envolvidos naquele momento.

Bosch e Gascón (2001) consideram as tarefas que solicitamos na formação como rotineiras; percebemos que, para esses professores a preparação de aula ocorre basicamente pela reprodução de livros didáticos sem reflexões profundas a respeito das escolhas que podem fazer em seu papel ativo para promoção da aprendizagem de seus alunos.

Embora tendo contato anterior com teorias preocupadas com a aprendizagem e com situações didáticas, diferentes das apresentadas nos livros didáticos durante a formação, apresentaram dificuldades em mudar suas práticas.

Constatamos que, conforme os professores avançavam em seus estudos, mais percebiam a fragilidade de seus conhecimentos sobre fracionários, mostrando a necessidade de uma formação que discutisse amplamente as concepções de fracionários, tipos de tarefas associadas a elas e possíveis técnicas mobilizadas nas resoluções dessas tarefas de acordo com a OM de referência.

No entanto, o retorno à produção da sequência mostrou a carência de autonomia desses professores, em idas e vindas estéreis para a concretização do que pretendiam por um bloqueio, típico como reação de adultos que percebem conhecimentos tidos como efetivos serem ameaçados.

$\mathrm{Na}$ busca de respostas para nossa segunda questão: É possivel encaminhar professores de matemática a reflexões que possibilitem mudanças nas concepções que têm de seus alunos proporcionando-lhes um novo lugar na instituição escolar?

Constatamos a possibilidade de mudança no olhar dos professores para seus alunos, quando permitimos que o professor observasse a prática de métodos de ensino flexíveis e interativos que deram para o aluno o lugar efetivo de aprendiz.

Assim, as discussões a respeito dos alunos, durante toda a formação, apontavam para sua falta de interesse e seus não saberes como impedimento de novas aprendizagens. A reflexão dessa deficiência na aprendizagem dos alunos como provocada pelo ensino ministrado, só ocorreu durante a aplicação da OD em uma sala de quinta série. Como prevíamos, os professores acreditavam que uma revisão do conteúdo seria suficiente.

No decorrer da formação, tivemos depoimentos de mudança de atitudes, tanto em relação ao conteúdo em jogo como nas relações desses professores com 
seus alunos. Eles tinham prazer de comentar durante os encontros cada pequeno avanço que percebiam construir em suas salas de aula, o que talvez tenha permitido que se mantivessem motivados para continuar participando do projeto.

Com certeza, esses avanços ocorreram de maneira diferente em cada professor, alguns se mostraram mais propícios às mudanças e arriscaram-se tentar implantá-las em suas aulas, outros, mais resistentes, testemunharam igualmente algumas mudanças, mas, com muito mais reservas.

Outro resultado significativo, também, em maior ou menor grau de intensidade, foi a constatação, por esses professores, da possibilidade de um trabalho que permita dar aos alunos alguma autonomia na construção de seus próprios conhecimentos. Esta percepção foi possibilitada pela observação objetiva de alunos em ação na sala de aula por esses professores.

Este tipo de mudança deve-se, provavelmente, a possibilidade de ver um professor mais experiente, do ponto de vista matemático e didático, atuando na sala de aula, interagindo, prevendo e solicitando a participação do aluno, bem como concluindo e institucionalizando os conteúdos de números fracionários trabalhados. Era como se esses professores soubessem, o que deveriam fazer, mas não como fazer.

Aliás, esta é uma necessidade que todos gostariam de ver satisfeita em suas formações, pois como afirmaram o discurso teórico que recebem cai no vazio porque não sabem como transformá-los em prática. Nesse aspecto merece a crítica aos estágios supervisionados das formações iniciais que, em sua maioria, não têm tal preocupação e a possibilidade de o professor em exercício ter um assessor que possa cumprir esse papel, para que haja uma efetiva mudança nas práticas dos professores em exercício.

Por outro lado, observamos que esses professores usavam os não saberes dos alunos, mais como um escudo de defesa do que pela observação e avaliação coerente desses alunos. Embora não possamos afirmar que lhes dão um novo lugar na instituição escolar, porque interferências externas (pais, escola, sistema escolar, ...) ainda não o permitem, vislumbram a possibilidade de uma aprendizagem efetiva dos alunos.

Nossas constatações são confirmadas por Estrela (1994), quando afirma que o professor, geralmente, "olha" para sua classe, mas não a vê, porque não sabe observar de forma objetiva seus alunos. Davis e Oliveira (1990) afirmam que é importante a interpretação que o professor faz do comportamento dos alunos, para que, de fato, exista a interação professor-alunos e estes possam construir seus conhecimentos.

Pretendendo responder nossa terceira questão: É possível em uma formação continuada promover ações que permitam aos professores alguma mudança em sua prática de ensino de números fracionários para uma quinta série? 
Percebemos que a falta de formação para tomadas de decisão que se apresentariam com o desenvolvimento de alguma autonomia, concorre como uma das prováveis causas das dificuldades apresentadas pelos professores.

Isso, provavelmente, porque estão acostumados a desempenhar seu papel, baseados em noções e princípios disponíveis na instituição escolar que não foram criadas por eles e, muitas vezes, são desconhecidas, porque foram instituídas em momentos históricos diferentes.

Constatamos que a formação inicial não os preparou nem para ensinar conteúdos matemáticos básicos, nem para desenvolverem autonomia suficiente para aprofundar esses conhecimentos ou se apropriar de resultados de pesquisa, que lhes poderiam auxiliar a melhor ensinar.

As emoções e sentimentos explicitados claramente no segundo mapa conceitual foram o ponto chave para as mudanças dos professores, da percepção de desequilíbrio de seus conhecimentos de fracionários ao entusiasmo de ver os alunos trabalhando em grupo e gostando da régua de polegadas, que haviam rejeitado durante a elaboração do material. O fato é que esse desequilíbrio foi necessário para promover a aprendizagem do conteúdo e de alguma autonomia.

As concepções que os professores tinham no início da formação a respeito de fracionários funcionaram na realidade como um bloqueio a novas realidades, não permitindo diferentes possibilidades de atuação e compreensão. Um tema considerado de pleno domínio pelos professores, quando colocado para uma reflexão mais profunda deixa-os embaraçados, tanto do ponto de vista emocional como em relação ao discurso que fazem sobre o não saber de seus alunos.

Entendemos que a possibilidade de mudança na prática de ensino de fracionários de professores em exercício pode ser conquistada com ações formativas planejadas, para que os professores possam refletir profundamente não só sobre as práticas, mas também sobre seus conhecimentos desse conteúdo.

No entanto, não podemos afirmar categoricamente que nossa formação propiciou tal resposta, visto que não os acompanhamos ensinando em suas próprias salas de aula, embora vários depoimentos apresentados revelem alguns indícios de mudanças de atitudes não, necessariamente, relativas ao tema de nosso estudo.

De qualquer forma, o material de ensino produzido durante a formação foi aceito pela professora da classe de quinta série onde foi aplicado e ela mostrou interesse em adotá-lo, mesmo sem fazer parte do grupo em formação. Esse querer, logo foi incorporado pelos professores do grupo no sentido de auxiliá-la no que fosse preciso, para que o material pudesse ser utilizado não só por essa professora, mas também por outros professores de quinta série. No entanto, esta é uma perspectiva de mudança que não pudemos acompanhar em nossos estudos.

Outro resultado mostrou-nos que uma formação colaborativa deve ser planejada por ações formativas globais que conduzam os professores a agir e refletir, 
tanto sobre suas ações como sobre suas carências didáticas e pedagógicas. Esse planejamento inicial é modificado, de acordo com as necessidades que se apresentam, por decisões que se traduzem em ações pontuais que devem ser tomadas de imediato, pois sem elas, provavelmente, estas conclusões poderiam não ter acontecido.

No entanto, o formador deve estar preparado para agir em momentos difíceis, tanto no sentido de manter a confiança do professor no formador, sem a qual nada pode ser feito como para mostrar sensibilidade aos percalços que enfrentam, sem perder a direção e os propósitos da formação.

Do ponto de vista teórico, nossos resultados confirmam as afirmações de Chevallard (1999) a respeito das ações do professor, quando se prepara para ensinar um conteúdo "observando" um ou vários livros didáticos, "analisando", geralmente, de maneira superficial o conteúdo, “avaliando" esse conteúdo para finalmente, "desenvolver" sua própria obra.

Da mesma forma, confirmam os estudos de Balacheff (1995) quando afirma que é possível a coabitação em um sujeito de conhecimentos contraditórios aos olhos de um observador que relaciona as situações como aos olhos do sujeito estas são vistas como distintas, o que talvez justificaria a dificuldade dos professores fazer relações de forma geral.

Por outro lado, as concepções dos professores a respeito de fracionários funcionaram como filtro de acordo com Ponte (1992) bloqueando novas realidades e novas possibilidades de atuação. Provavelmente, na medida que as reflexões explicitam os conhecimentos contraditórios citados por Balacheff, os professores utilizam-nos como escudo no sentido de evitar prováveis desequilíbrios. Por outro lado, Schulmann (1987) afirma que o professor deve compreender a fundo a matéria que ensina, pois, esta é a fonte principal da compreensão por parte do aluno.

Mas, para Davis e Oliveira (1990) afeto e cognição constituem aspectos inseparáveis que estão presentes em qualquer atividade e o afeto é a energia, para que a estrutura cognitiva passe a operar. Nesse sentido, Day (1999, apud Saraiva e Ponte, 2003) acredita que é preciso apoiar as ansiedades que acompanham as dificuldades provocadas pela mudança e dar tempo, para que os professores reflitam porque um dos obstáculos a mudança é a insegurança pessoal. Mudança esta que, para Saraiva e Ponte (2003) é possível quando o professor se desenvolve e não é "desenvolvido", pois a mudança deve ser interiorizada em níveis cada vez mais profundos. 